\title{
Toxocara canis
}

National Cancer Institute

\section{Source}

National Cancer Institute. Toxocara canis. NCI Thesaurus. Code C125963.

A species of parasitic nematodes in the genus Toxocara where canids are the definitive host. Human infection occurs through the accidental ingestion of infective larvae in the tissues of other terrestrial mammals, which serve as paratenic hosts. Toxocara canis is the most common cause of toxocariasis in humans. 